\title{
Effect of Cysteamine on Cytosolic Somatostatin Binding Sites in Rabbit Duodenal Mucosa ${ }^{1}$
}

\author{
L. Gonzalez-Guijarro, M. P. Lopez-Ruiz, G. Bodegas, J. C. Prieto \\ AND E. ARILLA ${ }^{2}$
}

Departamento de Bioquímica y Biología Molecular, Universidad de Alcalá de Henares, Madrid, Spain

Received June 20, 1986, and in revised form September 29, 1986

\begin{abstract}
Administration of cysteamine in rabbits elicited a rapid depletion of both duodenal mucosa and plasma somatostatin. A significant reduction was observed within 5 min, returning toward control values by $150 \mathrm{~min}$. The depletion of somatostatin was associated with an increase in the binding capacity and a decrease in the affinity of both high- and low-affinity binding sites present in cytosol of duodenal mucosa. Incubation of cytosolic fraction from control rabbits with $1 \mathrm{~m} M$ cysteamine did not modify somatostatin binding. Furthermore, addition of cysteamine at the time of binding assay did not affect the integrity of ${ }^{125} \mathrm{I}_{-} \mathrm{Tyr}^{11}$. somatostatin. It is concluded that in vivo administration of cysteamine to rabbits depletes both duodenal mucosa and plasma somatostatin and leads to up-regulation of duodenal somatostatin binding sites. 1987 Academic Press, Inc.
\end{abstract}

\section{INTRODUCTION}

Although the precise mechanisms of somatostatin action are still unknown, the initial step appears to be an interaction of the hormone with specific binding sites in target cells (Schonbrunn and Tashjian, 1978; Enjalbert et al., 1982). Binding sites for somatostatin have been characterized in a variety of endocrine and nonendocrine cells (Enjalbert et al., 1982; Bhathena et al., 1981). The control mechanisms which allow somatostatin to act on a tissue or at a particular subcellular site or biochemical pathway must be very finely tuned by specific regulation (Sussman et al., 1982). The magnitude of somatostatin action must be modulated by its ambient concentration, the number and/or the affinity of its binding sites, and the activity of yet unidentified intracellular postbinding events (Draznin, 1985). A central thesis is that the concentration of somatostatin binding sites can undergo rapid change, which may be of paramount importance in determining the degree of somatostatin action in diverse tissues (Srikant and Heisler, 1985). Szabo and Reichlin (1981) have observed that oral administration of the ulcerogen cysteamine rapidly depletes immunoreactive somatostatin in the gastrointestinal tract. This depletion of somatostatin is dose dependent and cannot be accounted for by release of either compound (Szabo and Reichlin, 1985). Furthermore, cysteamine-induced depletion of somatostatin has been shown to affect physiological processes mediated by somatostatin such as duodenal motility (Pihan et al., 1985).

In the present study we have used cysteamine as a tool to deplete both duodenal and plasma somatostatin levels in order to investigate the regulation by somatostatin of its own binding sites in cytosol of rabbit duodenal mucosa. In

\footnotetext{
' Supported by Grant 85/1213 from the Fondo de Investigaciones Sanitarias de la Seguridad Social.

${ }^{2}$ To whom correspondence and reprint requests should be addressed.
} 
addition, the in vitro direct action of cysteamine upon somatostatin binding was determined.

\section{METHODS}

Somatostatin-14 was kindly provided by Serono (Spain); synthetic $\mathrm{Tyr}^{11}$-somatostatin was purchased from Universal Biologicals Ltd. (Cambridge, England); trypsin inhibitor, bovine serum albumin (fraction V), and cysteamine- $\mathrm{HCl}$ were from Sigma (St. Louis, MO), and carrier-free $\mathrm{Na}^{125}$ I (IMS $30,100 \mathrm{mCi} / \mathrm{ml}$ ) was from the Radiochemical Centre (Amersham, UK). Synthetic Tyr ${ }^{11}$-somatostatin was radioiodinated by a chloramine-T method (Greenwood et al., 1963). The specific radioactivity of ${ }^{125} \mathrm{I}_{-\mathrm{Tyr}}{ }^{11}$-somatostatin was about $350 \mathrm{Ci} / \mathrm{g}$. All other chemicals were reagent grade.

New Zealand male rabbits weighing $2-3 \mathrm{~kg}$ were given cysteamine- $\mathrm{HCl}$ per os in a single dose of $70 \mathrm{mg} / 100 \mathrm{~g}$ body wt in distilled water. Controls received distilled water alone. The animals were killed by decapitation at various times after cysteamine administration, and the proximal duodenum was immediately removed. Trunk blood was collected in chilled tubes containing $1000 \mathrm{kIU} / \mathrm{ml}$ aprotinin and $1.2 \mathrm{mg} / \mathrm{ml}$ EDTA and immediately centrifuged; plasma was stored at $-70^{\circ} \mathrm{C}$ until assay. Somatostatin immunoreactivity in duodenal mucosa was extracted in $1 \mathrm{M}$ acetic acid at $0^{\circ} \mathrm{C}$ by sonication. Peptide concentration was measured by a radioimmunoassay method (Gerich et al., 1979) with a limit of sensitivity of $10 \mathrm{pg} / \mathrm{ml}$. Cytosol of duodenal mucosa was isolated as previously reported (Reyl-Desmars and Lewin, 1982). Protein concentration was estimated by the method of Lowry et al. (1951), using bovine serum albumin as a standard.

Cytosol fraction of fundic mucosa $(0.2 \mathrm{mg}$ protein $/ \mathrm{ml})$ was incubated at $25^{\circ} \mathrm{C}$ for $60 \mathrm{~min}$ in $0.5 \mathrm{ml}$ of a medium $(\mathrm{pH} \mathrm{7.4)}$ of the following composition: $0.5 \mathrm{mM}$ $\mathrm{NaH}_{2} \mathrm{PO}_{4}, 1 \mathrm{~m} M \mathrm{Na}_{2} \mathrm{HPO}_{4}, 80 \mathrm{~m} M \mathrm{NaCl}, 5 \mathrm{~m} M \mathrm{KCl}, 1 \mathrm{~m} M \mathrm{CaCl}_{2}, 1.5 \mathrm{~m} M$ $\mathrm{MgCl}_{2}, 50 \mathrm{~m} M$ Hepes ( $\left(N\right.$-2-hydroxyethyl)piperazine- $N^{\prime}$-2-ethanesulfonic acid), $11 \mathrm{mM}$ glucose, $0.1 \%$ bovine serum albumin, $0.1 \mathrm{mg} / \mathrm{ml}$ trypsin inhibitor, and 50

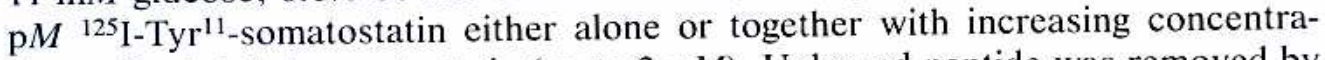
tions of unlabeled somatostatin (up to $2 \mu M$ ). Unbound peptide was removed by adding $1 \mathrm{ml} 0.25 \%$ activated charcoal, $0.5 \%$ bovine serum albumin, and $0.025 \%$ T-70 dextran (Reyl and Lewin, 1982). "Specific" binding was estimated as the difference between "total" binding (i.e., in the presence of tracer alone) and "nonspecific" binding (as measured in the presence of $4 \mu M$ unlabeled somatostatin); this nonspecific component represented about $45 \%$ of the binding observed in the absence of unlabeled somatostatin and was not modified by addition of $1 \mathrm{~m} M$ cysteamine. The integrity of bound ${ }^{125} \mathrm{I}_{-} \mathrm{Tyr}^{11}$-somatostatin was assessed by talc adsorption (Arilla et al., 1984).

Statistical analysis was done with Student's $t$ test for unpaired samples, differences with $P$ values lower than 0.05 being considered significant. Each individual experiment was performed in triplicate. All results are expressed as the mean values \pm SEM.

\section{RESULTS}

As shown in Fig. 1, cysteamine elicited a significant depletion of both duodenal mucosa and plasma somatostatin levels within $5 \mathrm{~min}$, returning toward control values by $150 \mathrm{~min}$. 


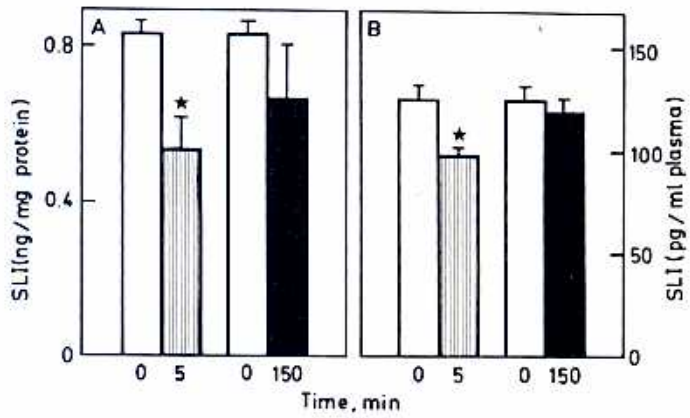

FIG. 1. Time course of cysteamine-induced depletion of somatostatinlike immunoreactivity (SLI) in rabbit duodenal mucosa $(A)$ and plasma (B). Values are expressed as the means \pm SEM of five triplicate determinations. The significance of the differences with respect to control values is given by $P<0.05$ (asterisk).

All cytosolic preparations showed a similar extent (about 30\%) of somatostatin degradation at the end of the incubation period, thus ruling out the possibility of misinterpreting the stoichiometric results. Depletion of endogenous somatostatin after in vivo cysteamine administration was associated with a time-dependent change in both binding capacity and affinity of duodenal mucosa somatostatin binding sites. Analysis of the competitive inhibition by somatostatin of the specific binding of ${ }^{125} \mathrm{I}_{-} \mathrm{Tyr}^{11}$-somatostatin revealed a cysteamine-induced decrease of affinity, as evidenced by a shift to the right of the inhibition curves (Fig. 2, left panel). When analyzing the stoichiometric data by the method of Scatchard (1949), the values of somatostatin binding to the cytosolic preparations exhibited curvilinear, concave upward curves that were analyzed on the basis of two classes of binding sites. A least-squares regression line was drawn to fit the lowaffinity' site using the four higher somatostatin concentrations. The contribution of this site was subtracted from the binding obtained at the lower somatostatin concentrations to obtain the high-affinity binding. Table I shows the corresponding equilibrium parameters for the high affinity-low capacity and for the low affinity-high capacity binding sites. The analysis of these results revealed a significant increase in the binding capacity of both high- and low-affinity binding sites at $5 \mathrm{~min}$ (but not at $150 \mathrm{~min}$ ) after cysteamine treatment, as compared to
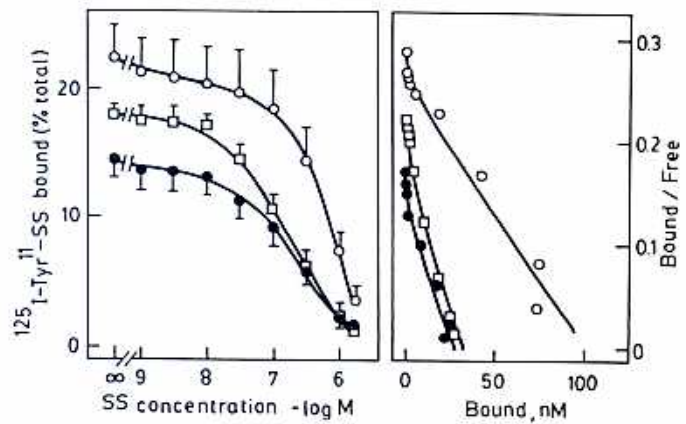

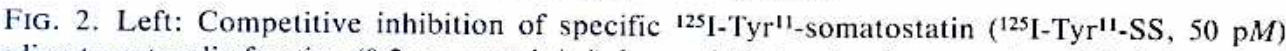
binding to cytosolic fraction $(0.2 \mathrm{mg}$ protein $/ \mathrm{ml})$ from rabbit duodenal mucosa by unlabeled somatostatin. Points correspond to control (-) and cysteamine-treated rabbits $5(O)$ and $150(\square)$ min after drug administration. Values are expressed as the means \pm SEM of five separate experiments, each performed in triplicate. Right: A Scatchard analysis of the same data. 
TABLE I

Effect of Cysteamine Administration on Equilibrium Parameters of Somatostatin Binding to Cytosol of Duodenal Mucosa ${ }^{a}$

\begin{tabular}{lccccc}
\hline & \multicolumn{3}{c}{ Somatostatin binding sites } \\
\cline { 2 - 3 } & \multicolumn{2}{c}{ High affinity } & & \multicolumn{2}{c}{ Low affinity } \\
\cline { 2 - 3 } \cline { 5 - 6 } & B.C. & $K_{d}$ & & B.C. & $K_{d}$ \\
\hline Control & $2.1 \pm 0.1$ & $18.4 \pm 2.9$ & & $129 \pm 18$ & $163 \pm 17$ \\
5 min & $3.1 \pm 0.1^{*}$ & $35.3 \pm 5.1^{*}$ & & $500 \pm 34^{*}$ & $380 \pm 58$ \\
$150 \mathrm{~min}$ & $1.9 \pm 0.1$ & $15.9 \pm 2.4$ & & $144 \pm 18$ & $148 \pm 20$ \\
\hline
\end{tabular}

Note. Dissociation constant: $K_{d}, \mathrm{n} M$. Binding capacity: B.C., pmole somatostatin/mg protein. Mean values $\pm \operatorname{SEM}(n=5)$. Significance versus control values, $* P<0.05$.

a Values were derived from the experimental data of Fig. 2 (right panel).

control values. The corresponding dissociation constant increased at the same time interval. To assess whether cysteamine exerts a direct action on somatostatin binding sites, it was included in the incubation medium at the time of the binding assay. The addition of $1 \mathrm{~m} M$ of cysteamine to the incubation medium did not change either binding capacity or affinity somatostatin binding sites (data not shown). To determine if cysteamine affects ${ }^{125} \mathrm{I}_{-} \mathrm{Tyr}^{11}$-somatostatin during the binding assay, the integrity of the ligand remaining free at the time of equilibrium binding in the presence and absence of $1 \mathrm{~m} M$ cysteamine was assessed. More than $70 \%$ of the ligand remained intact.

\section{DISCUSSION}

Present results show that cysteamine-induced depletion of immunoreactive somatostatin in both rabbit duodenal mucosa and plasma results in an increase in the number and a decrease in the affinity of both high- and low-affinity binding sites in the corresponding cytosolic preparation. A significant decrease (about $30 \%$ ) of somatostatin occurred as early as $5 \mathrm{~min}$ and returned toward control values by $150 \mathrm{~min}$ after cysteamine administration. That intestinal somatostatin depletion was not due to discharge into the blood was shown by the falling plasma levels of the peptide. Srikant and Patel (1984) have observed that cysteamine administration in rats led to a decrease of cerebrocortical somatostatin by a similar time-dependent pattern. However, Szabo and Reichlin (1981) have reported that duodenal somatostatin reached minimal levels $4 \mathrm{hr}$ after cysteamine intake. This discrepancy may be a result of differences in cysteamine doses and/or the animal species considered.

Despite the growing interest in cysteamine as an investigative tool for producing somatostatin deficiency, the mechanism of action of this agent remains unclear. It has been suggested by others that cysteamine might act by accelerating the intracellular degradation of immunoreactive somatostatin (Szabo and Reichlin, 1981) or, more likely, through a chemical modification of the disulfide bond which would render the molecule unreactive (Rivier et al., 1975). In any case, at the present time the role of somatostatin in experimental duodenal ulcer remains to be further investigated. Present results show that the cysteamine-induced depletion of immunoreactive somatostatin in both duodenal mucosa and plasma was associated with both an increase in the number and a decrease in the 
affinity of the two classes of cytosolic somatostatin binding sites. These data suggest that a decrease in somatostatin levels leads to sensitization or up-regulation of somatostatin binding sites in the duodenum and are consistent with a recent report showing that prolonged exposure of pituitary tumor cells to somatostatin resulted in a marked decrease in the density of somatostatin binding sites (Srikant and Heisler, 1985). Indeed, other authors (Srikant and Patel, 1984) have shown that cysteamine-induced depletion of brain somatostatin is associated with upregulation of the corresponding somatostatin binding sites. Furthermore the increase of hypothalamic somatostatin release after growth hormone administration caused a significant reduction in the interaction of the peptide hormone with pituitary membranes (Katakami et al., 1985). Thus, regulation of somatostatin binding sites appears to be similar to that of other hormone-binding sites systems (Kahn et al., 1973; Srikant et al., 1977; Lesniak and Roth, 1976). In another context, increasing site occupancy has been shown to be accompanied by decreased affinity in a variety of hormone-receptor systems (DeMeyts et al., 1976), as was found in the present work.

Interestingly, when added at the time of binding, cysteamine $(1 \mathrm{~m} M)$ did not affect either affinity or capacity of somatostatin binding sites. The reason for the difference between in vivo and in vitro effects of cysteamine on somatostatin binding sites is unclear. It is possible that normal regulation of somatostatin binding sites requires the intact cell. It should be noted that cysteamine has been shown to elicit lysosome activation (King, 1982). If lysosomal enzymes react with somatostatin binding sites it would lead to the observed decrease in the affinity values but it remains to be further investigated.

Somatostatin is an inhibitor of duodenal gastrin secretion (Bloom et al., 1974) and spontaneous intestinal contractions (Tansy et al., 1979) as well as a modulator of gastrointestinal mucus secretion (Johansson and Aly, 1982), processes that can be reversed by cysteamine administration (Pihan et al., 1985; Lichtenberger et al., 1977). Cysteamine-induced increases in the concentration of duodenal somatostatin binding sites could be a mechanism of adaptation, but it is possible that the corresponding low concentrations of somatostatin around target cells are below the threshold level.

\section{REFERENCES}

Arilla, E., Lopez-Ruiz, M. P., Gonzalez-Guijarro, L., Prieto, J. C., Gomez-Pan, A., and HiRST, B. H. (1984). Characterization of somatostatin binding sites in cytosolic fraction of rat intestinal mucosa. Biochim. Biophys. Acta 802, 203-208.

Bhathena, S. J., Louie, J., Schechter, G. P., Redman, R. S., Wahl, L., and Recant, L. (1981). Identification of human mononuclear leukocytes bearing receptors for somatostatin and glucagon. Diabetes 30, 127-135.

Bloom, S. R., Mortimer, C. H., Thorner, M. O., Besser, G. M., Hall, R., Gomez-Pan, A., Roy, V. M., Russel, R. C., CoY, D. H., Kastin, A. J., and Schally, A. V. (1974). Inhibition of gastrin and gastric-acid secretion by growth-hormone release-inhibiting hormone. Lancet 2 , $1106-1109$.

DeMeyts, P., BiAnCO, A. F., and Roth, J. (1976). Site-site interactions among insulin receptors. Characterization of the negative cooperativity. J. Biol. Chem. 251, 1877-1888.

DraZnIN, B. (1985). Somatostatin receptors in endocrine cells. In "The Receptors" (P. M. Conn, Ed.), Vol. 2, pp. 401-422. Academic Press, Orlando, FL.

Enjalbert, A., Tapia-Arancibia, L., Rieutort, M., Brazeau, P., Kordon, C., and Epelbaum, J. (1982). Somatostatin receptors on rat anterior pituitary membranes. Endocrinology 110, $1634-1640$. 
Gerich, J., Greene, K., Hara, M., Rizza, R., and Patron, G. (1979). Radioimmunoassay of somatostatin and its application in the study of pancreatic somatostatin secretion in vitro. J. Lab. Clin. Med. 93, 1009-1017.

Greenwood, F. C., Hunter, W. M., and Glover, J. S. (1963). The preparation of ${ }^{131}$ I-labelled human growth hormone of high specific radioactivity. Biochem. J. 89, 114-123.

JOHANSSON, C., and ALY, A. (1982). Stimulation of gastric mucus output by somatostatin in man. Eur. J. Clin. Invest. 12, 37-39.

KAHN, C. R., Neville, D. M., JR., and Roth, J, (1973). Insulin receptor interaction in the obese hyperglycemic mouse. A model of insulin resistance. J. Biol. Chem. 248, 244-250.

Katakami, H., Berelowitz, M., Marbach, M., and Frohman, L. A. (1985). Modulation of somatostatin binding to rat pituitary membranes by exogenously administered growth hormone. Endocrinology 117, 557-560.

KING, L. W. (1982). Somatostatin depletion by cysteamine in cultured brain cells. In "Proceedings, 64th Annual Meeting, Endocrine Society," p. 138. San Francisco.

LESNIAK, M. A., and RoTH, J. (1976). Regulation of receptor concentration by homologous hormone. Effect of human growth hormone on its receptor in IM-9 lymphocytes. J. Biol. Chem. 251, $3720-3729$.

Lichtenberger, L. M., Szabo, S., and Trier, J. S. (1977). Duodenal ulcerogens, cysteamine and propionitrile, stimulate serum gastrin levels in the rat. Gastroenterology 73, 1305-1308.

Lowry, O. H., Rosebrough, N. J., FARR, A. L., and RANDALl, R. J. (1951). Protein measurement with the Folin phenol reagent. J. Biol. Chem. 193, 265-275.

Pihan, G., Kline, T. J., Hollenberg, N. K., and Szabo, S. (1985). Duodenal ulcerogens cysteamine and proprionitrile induce gastroduodenal motility alterations in the rat. Gastroenterology 88 , 989-997.

REYL, F. J., and LEWIN, M. J. M. (1982). Intracellular receptor for somatostatin in gastric mucosal cells. Decomposition and reconstitution of somatostatin-stimulated phosphoprotein phosphatases. Proc. Natl. Acad. Sci. USA 76, 978-982.

REYL-Desmars, F., and LEwIN, M. J. M. (1982). Evidence for an intracellular somatostatin receptor in pancreas: A comparative study with reference to gastric mucosa. Biochem. Biophys. Res. Commun. 109, 1321-1331.

Rivier, J., Brazeau, P., Vale, W., and Guillemin, R. (1975). Somatostatin analogs: Relative importance of the disulfure bridge and of the Ala-Gly side chain for biological activity. J. Med. Chem. $18,123-126$.

SCATCHARD, G. (1949). The attraction of protein for small molecules and ions. Ann. N.Y. Acad. Sci. $51,660-672$.

SChOnbrunN, A., and TAShJiAn, A. H., JR. (1978). Characterization of functional receptors for somatostatin in rat pituitary cells in culture. J. Biol. Chem. 253, 6473-6483.

Srikant, C. B., and Heisler, S. (1985). Relationship between receptor binding and biopotency of somatostatin-14 and somatostatin-28 in mouse pituitary tumor cells. Endocrinology 117, 271-278.

SRIKANT, C. B., and PATEl, Y. C. (1984). Cysteamine-induced depletion of brain somatostatin is associated with up-regulation of cerebrocortical somatostatin receptors. Endocrinology, 115, 990-995.

Srikant, C. B., Freeman, D., McCorkle, K., and Unger, R. H. (1977). Binding and biologic activity of glucagon in liver cell membranes of chronically hyperglucagonemic rats. $J$. Biol. Chem. 252, 7434-7436.

Sussman, K. E., Mehler, P. S., Leitner, J. W., and Draznin, B. (1982). Role of the secretion vesicle in the transport of receptors: modulation of somatostatin binding to pancreatic islets. Endocrinology 111, 316-323.

Szabo, S., and Reichlin, S. (1981). Somatostatin in rat tissues is depleted by cysteamine administration. Endocrinology 109, 2255-2257.

Szabo, S., and Reichlin, S. (1985). Somatostatin depletion by cysteamine: Mechanism and implication for duodenal ulceration. Fed. Proc. 44, 2540-2545.

Tansy, M. F., Martin, J. S., Landin, W. E., and Kendall, F. M. (1979). Species difference in GI motor response to somatostatin. J. Pharm. Sci. 68, 1107-1113. 